\title{
Evaluation of E-Learning Web Sites Using Fuzzy Axiomatic Design Based Approach
}

\author{
Gülçin Büyüközkan \\ Department of Industrial Engineering, Galatasaray University \\ Çırağan Caddesi No: 36 Ortaköy, Istanbul, 34357, Turkey \\ E-mail: gulcin.buyukozkan@gmail.com \\ www.gsu.edu.tr \\ Jbid Arsenyan \\ Department of Industrial Engineering, Bahçeşehir University \\ Çrağan Caddesi Osmanpaşa Mektebi Sokak No: 4-6, Beşiktaş, Istanbul, 34100, Turkey \\ E-mail: jbid.arsenyan@bahcesehir.edu.tr \\ www.bahcesehir.edu.tr \\ Gürdal Ertek \\ Faculty of Engineering and Natural Sciences, Sabancı University \\ Orhanl, Tuzla, Ístanbul, 34956, Turkey \\ E-mail:ertekg@sabanciuniv.edu \\ www.sabanciuniv.edu \\ Received: 01-11-2009 \\ Accepted: 02-12-2009
}

\begin{abstract}
High quality web site has been generally recognized as a critical enabler to conduct online business. Numerous studies exist in the literature to measure the business performance in relation to web site quality. In this paper, an axiomatic design based approach for fuzzy group decision making is adopted to evaluate the quality of e-learning web sites. Another multi-criteria decision making technique, namely fuzzy TOPSIS, is applied in order to validate the outcome. The methodology proposed in this paper has the advantage of incorporating requirements and enabling reductions in the problem size, as compared to fuzzy TOPSIS. A case study focusing on Turkish elearning websites is presented, and based on the empirical findings, managerial implications and recommendations for future research are offered.
\end{abstract}

Keywords: Fuzzy axiomatic design, Group decision making, Web site quality, E-Learning web sites, Fuzzy TOPSIS.

\section{Introduction}

E-Learning, one of the e-service applications, is a wide set of applications and processes that manage diverse types of electronic media to deliver vocational education and training (Aladwani and Palvia, 2002). For e-learning service providers, the Internet serves as the primary interface with the e-learners, since the elearning web site has a much more extended function, compared to conventional web sites, which only disseminate information about services and products. Consequently, the web site quality should be considered 
as a critical success factor for e-learning service providers. Especially, in the case of vital education or training services, the web site quality and its evaluation should be studied in a more detailed manner from elearners' perspective (Colette, 2001).

In a number of publications, quantitative methods are adopted for the evaluation of web site quality, with statistical methods ranking as the most widely used assessment tools (Chao, 2002; Cox and Dale, 2002; Jeong et al., 2003; Kim et al., 2003; Kim and Stoel, 2004; Toms and Taves, 2004). Additionally, other methods such as multidimensional scaling and correspondence analysis (Van der Merwe and Bekker, 2003), weighted scores (Barnes and Vidgen, 2003), index method (González and Palacios, 2004), soft computing technologies (Hwang et al., 2004) and multi criteria decision making (MCDM) (Bilsel et al., 2006) are also used in assessing and improving the web site quality. Nonetheless, there exist few studies comparing customer needs to web sites performance. Axiomatic Design (AD) principles (Suh, 2001) provide a powerful tool to measure how well system capabilities respond to functional requirements. The ultimate goal of $\mathrm{AD}$ is to establish a scientific basis for design and to improve design activities. This is achieved through providing the designer with a theoretical foundation based on logical and rational thought process and tools. Even though $\mathrm{AD}$ is traditionally applied to the design of physical entities, there exist studies that employ $\mathrm{AD}$ in designing intangible systems as proposed in this study, such as ecommerce strategies (Martin and Kar, 2002) and ecommercial web sites (Yenisey, 2007).

Conventional information content approach cannot be used in the case of incomplete information, since, the expression of system and design ranges by crisp numbers would be ill defined (Kahraman and Kulak, 2005). For this reason, under incomplete information, the subjectivity and vagueness in the assessment process is dealt with fuzzy logic (Zadeh, 1975). The information axiom of $\mathrm{AD}$ is utilized as a fuzzy MCDM technique by Kulak and Kahraman (2005a). However, while there exist many applications of AD methodology (Suh, 2001) in literature, there are relatively few studies on fuzzy AD applications for MCDM. [Kahraman and Kulak (2005a, 2005b); Kulak (2005); Yücel and Aktas (2008); Kahraman and Cebi (2009); Celik et al. (2009a); (Celik et al., 2009b); Celik (2009); Cevikcan et al. (2009)] On the other hand, the literature does not offer a fuzzy AD based MCDM approach to the web site evaluation problem.

The aim of this paper is to attain a group consensus on functional requirements of an ideal e-learning web site. A case study is then conducted in order to evaluate several e-learning web sites according to these functional requirements with group fuzzy AD. Fuzzy $\mathrm{AD}$ methodology is based on the conventional AD; however, crisp ranges are replaced by fuzzy numbers that represent linguistic terms. For measuring intangible criteria such as reliability, responsiveness, etc., fuzzy $\mathrm{AD}$ is applied to translate linguistic terms into performance measures. Also, group consensus is sought throughout the study and therefore, fuzzy AD model is enhanced with a group decision making tool.

The paper is organized as follows. In next section, elearning web site evaluation criteria are defined. Section 3 briefly describes the proposed fuzzy $\mathrm{AD}$ based evaluation methodology. A case study is conducted in elearning web sites evaluation and the outcomes are explained in Section 4. The concluding remarks are given in the last section.

\section{Evaluation criteria for e-learning web sites}

Internet-oriented applications aim at satisfying current educational needs by closing the gap between traditional educational techniques and future trends in technologyblended education (Tzouveli et al., 2008), enabling a new type of education on online platforms. E-Learning refers to Internet technologies used to deliver a broad array of solutions that support the instructional process in a networked environment through the establishment of an interactive virtual classroom (Poon et al., 2004). The expected outcomes of online teaching and learning are largely dependent on the quality of the teaching processes and the effectiveness of online access. To this end, e-learning systems must be designed and constructed cautiously, especially while applying a scientific approach with well-designed procedures and techniques. The ultimate goal is to accomplish an effective and high quality learning system, comparable with the traditional educational systems (Colette, 2001). Web sites appear as the primary interface to the end user (e-learner) and user satisfaction vis-à-vis humancomputer interaction determines the quality of the elearning provider. An organization with a poor web site or ineffective services may project weaken the organization's image and position. Hence, determining 
evaluation criteria for e-learning web sites is important in order to determine user needs (Ahn et al., 2007). In this context, an e-learning web site quality has to be analyzed in a more detailed manner.

Literature offers numerous studies investigating eservice and e-learning web site evaluation criteria. Webb and Webb (2004) states that a business to customer (e-learning provider to e-learner, in our context) web site quality is directly affected by service quality and information quality. According to Ahn et al. (2007), even though web site evaluation criteria may vary, the main categories include system, information, and service quality. System quality (such as interface design and functionality), is an engineering oriented performance characteristic while information quality (such as completeness and timeliness) has both engineering and operational characteristics. Service quality refers to availability of communication, mechanisms for accepting consumer complaints and their timely resolution with responsiveness, assurance, and follow-up services. According to the survey conducted by Poon et al. (2004), five main factors influence the effectiveness of e-learning process: students' behavior, characteristics of lecturers, interactive application, technology or system, and the institutions. On the other hand, Mahdavi et al. (2008) state that e-learner satisfaction can be classified into four dimensions: content, personalization, learning community, and learner interface. Kim and Lee (2008) detect two principle factors for learning management systems. Factor I consists of instruction management, screen design, and technology; whereas Factor II consists of interaction and evolution. McPherson and Nunest (2008) investigate the critical success factors required to deliver e-learning within higher education programs and they cite five fundamental aspects of elearning: organizational, technological, curriculum design, instructional design and e-learning course delivery.

Based on an in-depth literature analysis, results of industrial surveys and in the light of the expert suggestions, seven main criteria were determined as the e-learning web site quality dimensions in this study. Ahn et al. (2007) state that technology-focused approach considers the web site as an information system, while service-focused approach sees a web site as a service provider. Following criteria were determined with a point of view combining the two approaches:

- Right and Understandable Content (C1): This criterion includes credibility, clearness and succinctness. While using educational web sites, authority is a particular concern, as high quality content must be assured. Instructional objectives should also be assured. In addition, the content should be easily understood, unambiguous and succinct (Smith, 2001; Aladwani and Palvia, 2002; Chao, 2002; Cox and Dale, 2002; Dragulanescu, 2002; Jeong et al., 2003; van der Merwe and Bekker, 2003; Wang, 2003; Hwang et al., 2004; Barnes and Vidgen, 2006; Büyüközkan et al., 2007; Grigoroudis et al., 2008; van den Haak et al., 2009).

- Complete Content (C2): This criterion includes accuracy and coverage. The purpose of this assessment is to guarantee that the content is actually correct: up to date, factual, detailed, exact and comprehensive. This criterion also assesses the existence of tests, quizzes and exams for adequate evaluation procedures (Smith, 2001; Aladwani and Palvia, 2002; Chao, 2002; Cox and Dale, 2002; Dragulanescu, 2002; Jeong et al., 2003; van der Merwe and Bekker, 2003; Wang, 2003; Hwang et al., 2004; Kim and Stoel, 2004; Barnes and Vidgen, 2006; Büyüközkan et al., 2007; Grigoroudis et al., 2008; van den Haak et al., 2009).

- Personalization (C3): This dimension states a level of individualization. This can make the web site more attractive for the e-learners (Aladwani and Palvia, 2002; Wang, 2003; Barnes and Vidgen, 2006; Büyüközkan et al., 2007).

- Security (C4): This dimension comprises criteria that may be used for evaluating the security of a web site. A confident web site should assure the secrecy of its users' personal and private data. The scope of the privacy should be stated in the web site. In order to place such information in the web site, having a digital certificate is desirable (Smith, 2001; Aladwani and Palvia, 2002; Cox and Dale, 2002; van der Merwe and Bekker, 2003; Webb and Webb, 2004; Barnes and Vidgen, 2006; Büyüközkan et al., 2007; Gonzalez et al., 2007).

- Navigation (C5): This criterion describes the ability of web-based service systems to perform the online service consistently and accurately. It controls the organization and technical capabilities of the navigation through the pages (Smith, 2001; 
Aladwani and Palvia, 2002; Chao, 2002; Jeong et al., 2003; Kim et al., 2003; van der Merwe and Bekker, 2003; Webb and Webb, 2004; Barnes and Vidgen, 2006; Büyüközkan et al., 2007; Grigoroudis et al., 2008).

- Interactivity (C6): This dimension measures the availability of complementary functions of the traditional communication media to digital media. Availability of Frequently Asked Questions (FAQs), help and feedback systems constitute the content of this dimension. Adequate responsiveness is an important source of motivation for the elearners (Aladwani and Palvia, 2002; Büyüközkan et al., 2007; Dragulanescu, 2002; Smith, 2001; van der Merwe and Bekker, 2003).

- User Interface (C7): This criterion includes the design appearance, consistency, the information structure and the organization of the web site. Applications of the right design principles are essential. A consistent interface allows the elearners to follow the required tasks easily. The information structure and organization of the web site should also be easy to follow and to be understood by the e-learners (Büyüközkan et al., 2007; Grigoroudis et al., 2008; Kim et al., 2003;Smith, 2001; van den Haak et al., 2009; van der Merwe and Bekker, 2003; Wang, 2003).

\section{Fuzzy Axiomatic Design based Group Decision-Making Methodology}

In line with the multi-dimensional characteristics of web site quality, MCDM methodology is a powerful tool widely used for evaluating and ranking problems containing multiple, usually conflicting criteria. Over the years, several behavioral scientists, operational researchers and decision theorists have proposed a variety of methods describing how an evaluator might arrive at a preference judgment while choosing among the multiple alternatives. Hence, this work attempts to model the e-learning web site evaluation in an MCDM framework. In addition, the subjectivity and vagueness in the assessment process is dealt with fuzzy logic (Zadeh, 1975). Multiple decision makers (DMs) are often preferred rather than a single DM to avoid the bias and to minimize the partiality in the decision process (Herrera et al., 2001). Therefore, fuzzy MCDM with group decision is increasingly employed in literature (Lu et al., 2008; Li et al., 2008), as evaluation criteria become more intangible and the decision making becomes more complex to make for single DM. For example, Chen and Cheng (2005) apply fuzzy MCDM with group decision to information systems personnel selection. Wang and Parkan (2008) consider fuzzy preference aggregation problem in group decision and they apply it to the broadband internet service selection. Recently, Yeh and Chang (2009) develop a hierarchical weighting method in order to assess the weights of a large number of evaluation criteria by pairwise comparisons.

This paper proposes a set of evaluation criteria for elearning web sites, as well as a methodology to evaluate these web sites. Main steps of the proposed methodology are recapitulated in Figure 1. The first step in the methodology is determining e-learning web site evaluation criteria. In this study, criteria described in Section 2 are employed. These criteria undergo pairwise comparison by a group of DMs. Fuzzy Analytic Hierarchy Process (AHP) is then applied to compute the criteria weights. E-learning web site alternatives are identified and several sites are considered in order to cover all available services on the net. Then, alternatives and functional requirements are evaluated by DMs. These evaluations are translated into fuzzy numbers and then are aggregated. Information contents are calculated accordingly and alternatives that cannot meet the functional requirements are eliminated. The last step of fuzzy $\mathrm{AD}$ methodology is ranking the alternatives in respect to weighted information contents and selecting the best web site according to a decreasing order of information content. Finally, fuzzy TOPSIS technique is applied in order to compare the outcome of two methodologies.

Techniques employed in the study, namely Fuzzy $\mathrm{AD}$, fuzzy AHP, Chen's aggregation methodology and fuzzy TOPSIS are now described.

\subsection{Fuzzy Axiomatic Design}

$\mathrm{AD}$, a systematic method offering a scientific base for design, was introduced by Suh (1990) and its application areas include software design, quality system design, general system design, manufacturing system design, ergonomics, engineering systems, office cell design, and e-commerce strategies. AD is based on two axioms. The independence axiom states that the independence of functional requirements should be maintained and information axiom states that among the designs that satisfy the functional requirements, the design with the minimum information content is the best 


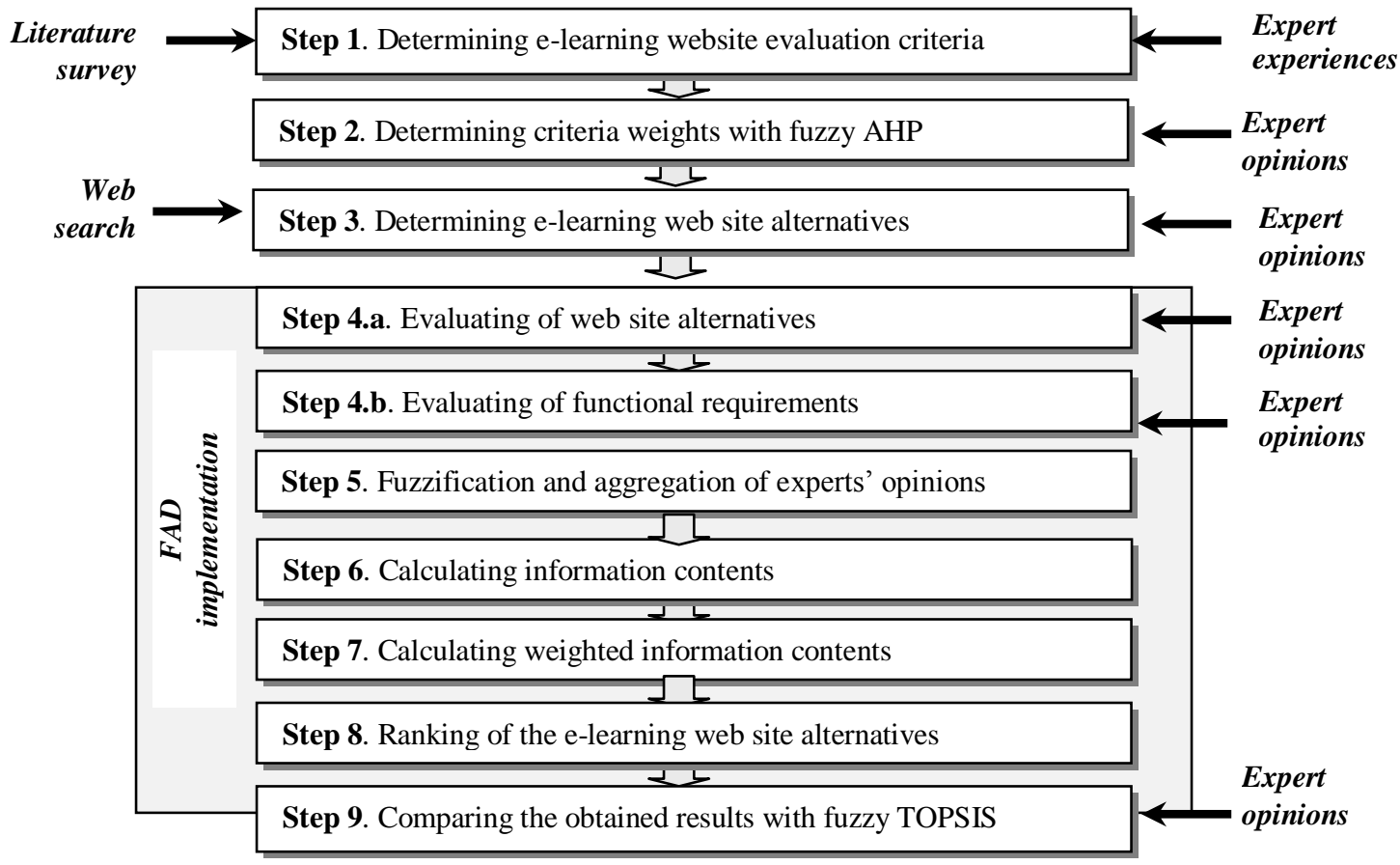

Fig. 1. Steps of the proposed methodology

design. Information content, on which MCDM technique is based, represents a function of probability of satisfying a functional requirement $F R$. Therefore, the design with the highest probability to meet these requirements is the best design. Information content $I_{i}$ of a design with probability of success $p_{i}$ for a given $F R_{i}$ is defined as follows:

$$
I_{i}=\log _{2}\left(\frac{1}{p_{i}}\right)
$$

According to Suh (2001), logarithm is employed in calculating the information contents, so as to attain additivity.

On the other hand, the probability of success is given by the design range (the requirements for the design) and the system range (the system capacity). Figure 2 illustrates the design and system ranges as well as the common area. The intersection of the ranges offers the feasible solution. Therefore, the probability of success can be expressed as:

$$
p_{i}=\int_{l}^{u} p\left(F R_{i}\right) d F R_{i}
$$

where $l$ and $u$ represent the lower and upper limits of the design range and where $p$ represents the probability distribution function of the system for a given $F R_{i}$.
The probability of success $p_{i}$ is equal to the common area $A_{c}$. Consequently, the information content can be expressed as follows:

$$
I_{i}=\log _{2}\left(\frac{1}{A_{c}}\right)
$$

Also, if the probability distribution function is uniform, the probability of success becomes:

$$
p_{i}=\frac{\text { common range }}{\text { system range }}
$$

Therefore, the information content can also be written as:

$$
I_{i}=\log _{2}\left(\frac{\text { system range }}{\text { common range }}\right)
$$

Fuzzy AD methodology is based on the conventional AD. However, crisp ranges are replaced by fuzzy numbers that represent linguistic terms (Figure 3). In this study, triangular fuzzy numbers (TFNs) are employed. Intersection of TFNs representing design and system ranges presents the common area (Kulak and Kahraman, 2005a). Firstly, the information content is calculated as in a non-fuzzy environment. Then information content in a fuzzy environment is calculated as follows: 


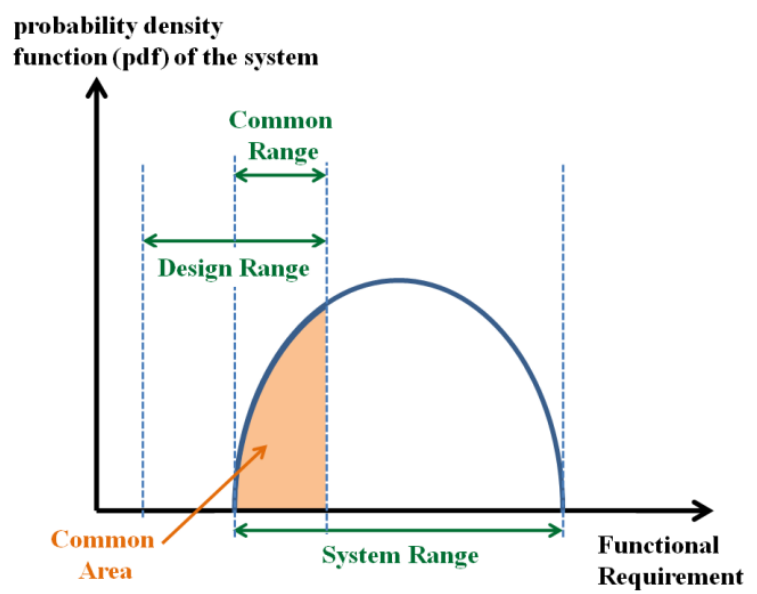

Fig. 2. System-Design ranges and common area.

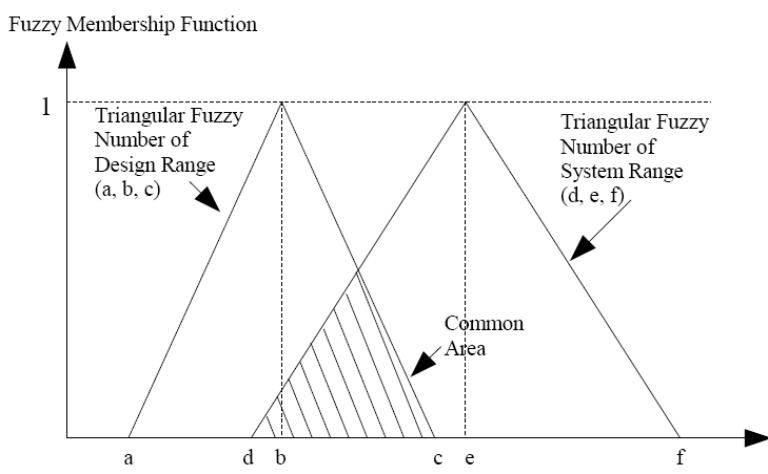

Fig. 3. System-design ranges and common area in fuzzy environment

$I_{i}=\left\{\begin{array}{cc}\infty & \text { no intersection } \\ \log _{2}\left(\frac{\text { Area of system range }}{\text { Common area }}\right), & \text { otherwise }\end{array}\right.$

In this study, the calculation of the weighted information content is adapted from Kahraman and Cebi (2008). This model requires determination of weights of criteria and sub-criteria. Total weighted information content for first level criteria is calculated as follows:

$$
I=\sum_{i=1}^{n} w_{i} I_{i}
$$

where $\mathrm{n}$ is the number of first level criteria and $\sum_{=1}^{n} w_{i}=1$.

Likewise, information content for second level criteria (sub-criteria for criterion $i$ ) is calculated as follows:

$$
I_{i}=\sum_{j=1}^{m} w_{i j} I_{i j}
$$

where $m$ is the number of sub-criteria for criterion $i$ and $\sum_{j=1}^{m} w_{i j}=1$ for $i=1, \ldots n$.

Finally, according to information axiom, alternatives are ranked with increasing order of information content.

\subsection{Fuzzy AHP}

It is not possible to assume that e-learning website evaluation criteria are of equal importance. There are many methods that can be employed to determine weights, such as eigenvector, weighted least square, entropy methods and diverse MCDM methods. In this study, the fuzzy extension of the one of the most outstanding MCDM approaches, AHP (Saaty, 1980) is used to determine the decision criteria weights. Despite its wide range of applications, the conventional AHP approach may not fully reflect a style of human thinking. One reason is that decision makers usually feel more confident to give interval judgments rather than expressing single numeric values. Furthermore, knowledge concepts and models contain tacit values and uncertainty, causing assessment and evaluation to be more difficult. This difficulty is handled by applying AHP in fuzzy environment to solve prioritisation and evaluation problems.

Firstly advocated by Zadeh (1965), fuzzy set theory has become important to deal with the ambiguity in a system. In this study, firstly linguistic terms are used to represent the expert assessments, then triangular fuzzy numbers, $\tilde{1}$ to $\tilde{9}$ as given in Table 1 , are used to represent subjective pair-wise comparisons of evaluation processes in order to capture the vagueness.

The four step computational procedure is given as follows: 
Table 1. Definition and membership function of fuzzy number (Saaty, 1989)

\begin{tabular}{cclc}
\hline Intensity of Importance & Fuzzy Number & Definition & Membership Function \\
\hline 9 & $\tilde{9}$ & Extremely more importance (EMI) & $(8,9,10)$ \\
7 & $\tilde{7}$ & Very strong importance (VSI) & $(6,7,8)$ \\
5 & $\tilde{5}$ & Strong importance (SI) & $(4,5,6)$ \\
3 & $\tilde{3}$ & Moderate importance $(\mathrm{MI})$ & $(2,3,4)$ \\
1 & $\tilde{1}$ & Equal importance (EI) & $(1,1,2)$
\end{tabular}

1. Compare the performance score. Triangular fuzzy numbers $(\tilde{1}, \tilde{3}, \tilde{5}, \tilde{7}, \tilde{9})$ are used to indicate the relative strength of each pair of elements in the same hierarchy.

2. Construct the fuzzy comparison matrix. By using triangular fuzzy numbers, via pair-wise comparison, the fuzzy judgment matrix $\tilde{A}\left(a_{i j}\right)$ is constructed as given below:

$$
\tilde{A}=\left[\begin{array}{cccc}
1 & \tilde{a}_{12} & \cdots & \tilde{a}_{1 n} \\
\tilde{a}_{21} & 1 & \cdots & \tilde{a}_{2 n} \\
\vdots & \vdots & \ddots & \vdots \\
\tilde{a}_{n 1} & \tilde{a}_{n 2} & \cdots & 1
\end{array}\right]
$$

where $\tilde{a}^{\alpha}{ }_{i j}=1$, if $I$ is equal to $j$, and $\tilde{a}^{\alpha}{ }_{i j}=\tilde{1}, \tilde{3}, \tilde{5}, \tilde{7}, \tilde{9}$ or $\tilde{1}^{-1}, \tilde{3}^{-1}, \widetilde{5}^{-1}, \tilde{7}^{-1}, \widetilde{9}^{-1}$, if $I$ is not equal to $j$.

3. Solve the fuzzy eigenvalue. A fuzzy eigenvalue, $\tilde{\lambda}$, is a fuzzy number solution to:

$$
\widetilde{\boldsymbol{A}} \widetilde{\boldsymbol{x}}=\tilde{\lambda} \widetilde{\boldsymbol{x}}
$$

where $\boldsymbol{A}$ is a $n \times n$ fuzzy matrix containing fuzzy numbers $\tilde{a}_{i j}$ and $\tilde{\boldsymbol{x}}$ is a non-zero $n \times 1$ fuzzy vector containing fuzzy number $\tilde{x}_{i}$. To perform fuzzy multiplications and additions by using the interval arithmetic and $\alpha$-cut, the equation $\widetilde{\boldsymbol{A}} \widetilde{\boldsymbol{x}}=\tilde{\lambda} \widetilde{\boldsymbol{x}}$ is equivalent to:

$$
\begin{aligned}
& {\left[a_{i 1 l}^{\alpha} x_{1 l}^{\alpha}, a_{i 1 u}^{\alpha} x_{1 u}^{\alpha}\right] \oplus \cdots \oplus\left[a_{i n l}^{\alpha} x_{n l}^{\alpha}, a_{i n u}^{\alpha} x_{1 u}^{\alpha}\right]} \\
& \quad=\left[\lambda x_{i l}^{\alpha}, \lambda x_{i u}^{\alpha}\right]
\end{aligned}
$$

where:

$$
\begin{gathered}
\tilde{\boldsymbol{A}}=\left[\tilde{a}_{i j}^{\alpha}\right], \tilde{\boldsymbol{x}}^{t}=\left(\tilde{x}_{1}, \ldots, \tilde{x}_{n}\right), \tilde{a}_{i j}^{\alpha}=\left[\tilde{a}_{i j l}^{\alpha}, \tilde{a}_{i j u}^{\alpha}\right], \\
x_{i}^{\alpha}=\left[x_{i l}^{\alpha}, x_{i u}^{\alpha}\right], \tilde{\lambda}^{\alpha}=\left[\lambda_{l}^{\alpha}, \lambda_{u}^{\alpha}\right]
\end{gathered}
$$

for $0<\alpha \leq 1$ and all $I, j$, with $I=1,2, \ldots, n$, $j=1,2, \ldots, n$.

The $\alpha$-cut is known to incorporate the experts or decision-maker(s) confidence over his/her preference or the judgments. The degree of satisfaction for the judgment matrix $\tilde{A}$ is estimated by the index of optimism $\mu$. A larger value of the index $\mu$ indicates a higher degree of optimism. The index of optimism is a linear convex combination (Lee, 1999) defined as:

$$
\tilde{a}_{i j}^{\alpha}=\mu \tilde{a}_{i j u}^{\alpha}+(1-\mu) \tilde{a}_{i j l}^{\alpha}, \forall \alpha \in[0,1]
$$

When $\alpha$ is fixed, the following matrix can be obtained after setting the index of optimism, $\mu$, in order to estimate the degree of satisfaction:

$$
\tilde{A}=\left[\begin{array}{cccc}
1 & \tilde{a}_{12}^{\alpha} & \cdots & \tilde{a}_{1 n}^{\alpha} \\
\tilde{a}_{21}^{\alpha} & 1 & \cdots & \tilde{a}_{2 n}^{\alpha} \\
\vdots & \vdots & \ddots & \vdots \\
\tilde{a}_{n 1}^{\alpha} & \tilde{a}_{n 2}^{\alpha} & \cdots & 1
\end{array}\right]
$$

The eigenvector is calculated by fixing the $\mu$ value and identifying the maximal eigenvalue. After defuzzification of each pair wise matrix, the consistency ratio $(C R)$ for each matrix is calculated. The deviations from consistency are expressed by the following equation consistency index, and the measure of inconsistency is called the consistency index $(C I)$ :

$$
C I=\frac{\lambda_{\max }-n}{n-1}
$$

The consistency ratio $(C R)$ is used to estimate directly the consistency of pair wise comparisons. The $C R$ is computed by dividing the $C I$ by a value obtained from a table of Random Consistency Index $(R I)$ to:

$$
C R=\frac{C I}{R I}
$$

If $C R$ is less than 0.10 , the comparisons are acceptable, otherwise not. $R I$ is the average index for randomly generated weights (Saaty, 1980).

4. The priority weight of each criterion can be obtained by multiplying the matrix of evaluation ratings by the vector of attribute weights and summing over all attributes.

\subsection{Aggregation methodology}

In this study, the fuzzy group decision-making method presented by Chen (1998) is employed in order 
to aggregate fuzzy opinions of the DMs. This method is recently employed by Celik et al. (2009).

The steps of the aggregation method are as follows:

1. Calculate the degree of agreement $S_{u, v}\left(W_{u}, W_{v}\right)$ of the opinions between each pair of experts $E_{u}$ and $E_{v}$ where $S_{u, v}\left(W_{u}, W_{v}\right) \in[0,1], \quad 1 \leq u \leq M, 1 \leq v \leq M$ and $u \neq v$.

Let $A$ and $B$ be two standardized triangular fuzzy numbers $A=\left(a_{1}, a_{2}, a_{3}\right), B=\left(b_{1}, b_{2}, b_{3}\right) \quad$ where $0 \leq a_{1} \leq a_{2} \leq a_{3} \leq 1$ and $0 \leq b_{1} \leq b_{2} \leq b_{3} \leq 1$.

Then the degree of similarity between the standardized triangular fuzzy numbers and can be measured by the similarity function:

$$
S(A, B)=1-\frac{\left|a_{1}-b_{1}\right|+\left|a_{2}-b_{2}\right|+\left|3-b_{3}\right|}{4}
$$

where $S(A, B) \in[0,1]$. The larger the value of $S(A, B)$, the greater is similarity between the standardized triangular fuzzy numbers $A$ and $B$. The equation $S(A, B)=S(B, A)$ is valid for the degree of similarity.

2. Calculate the average degree of agreement $A A\left(E_{u}\right)$ of expert $E_{u}, u=1,2, \ldots, M$, where:

$$
A A\left(E_{u}\right)=\frac{1}{M-1} \sum_{v=1, v \neq u}^{M} S_{u, v}\left(W_{u}, W_{v}\right)
$$

3. Calculate the relative degree of agreement $R A\left(E_{u}\right)$ of expert $E_{u}, u=1,2, \ldots, M$, where:

$$
R A\left(E_{u}\right)=\frac{A A\left(E_{u}\right)}{\sum_{u=1}^{M} A A\left(E_{u}\right)}
$$

4. Calculate the consensus degree coefficient $C C\left(E_{u}\right)$ of expert $E_{u}, u=1,2, \ldots, M$ where:

$$
C C\left(E_{u}\right)=\beta w_{e u}+(1-\beta) R A\left(E_{u}\right)
$$

$\beta(0 \leq \beta \leq 1)$ is a relaxation factor of the method and $w_{e u}$ is degree of importance of expert. It shows the importance of $w_{e u}$ over $R A\left(E_{u}\right)$.

5. The aggregation result of the fuzzy opinions is

$$
W_{A G}=C C\left(E_{1}\right) \otimes R_{1} \oplus \ldots C C\left(E_{M}\right) \otimes R_{M}
$$

where operators $\otimes$ and $\oplus$ are the fuzzy multiplication operator and the fuzzy addition operator, respectively. The method is independent of the type of membership functions being used (Chen, 1998; Celik et al., 2009).

\subsection{Fuzzy TOPSIS}

In our methodology, another MCDM method, namely TOPSIS is applied in order to compare with fuzzy AD outcome. TOPSIS is proposed by Chen and Hwang (1992) and the basic principle is that the optimal solution should have the shortest distance from the positive ideal solution and the farthest from the negative ideal solution.

In classical MCDM methods, including classical TOPSIS, all data are assumed to be known precisely. However, under many conditions, crisp data are inadequate to model real-life situations since human judgments including preferences are often vague and cannot be estimated with an exact numerical value (Saghafian and Hejazi, 2005). Linguistic terms present a more realistic assessment of subjective judgments and hence, fuzzy set theory aids to deal with biased or imprecise evaluations.

There are many examples of applications of fuzzy TOPSIS in literature (Saghafian and Hejazi, 2005) such as evaluation of service quality (Tsuar et al., 2002), intercompany comparison (Deng et al., 2000), aggregate production planning (Wang et al., 2004), facility location selection (Chu, 2002) and large scale nonlinear programming (Abo-Sina and Amer, 2005).

Fuzzy TOPSIS is applied in this study due to its basic concept and wide applications such as Qureshi et al. (2008) and Shih (2008). Moreover, TOPSIS is based on geometrical principles, similar to AD which also operates on a geometrical level. The technique is adapted from Chen (2000) and the steps of the methodology are as follows:

1. With $m$ alternatives, $n$ criteria and $k$ DMs, fuzzy MCDM problem can be expressed as:

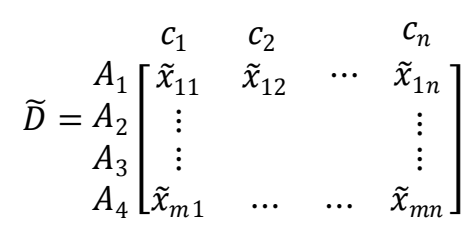

$\widetilde{D}$ represents the fuzzy decision matrix with alternatives $A$ and criteria $C$.

2. Aggregated judgments $\tilde{x}_{i j}$ are calculated as follows is

$$
\tilde{x}_{i j}=\frac{1}{k}\left(\tilde{x}_{i j}^{1}+\tilde{x}_{i j}^{2}+\cdots+\tilde{x}_{i j}^{k}\right)
$$

where $\tilde{x}_{i j}^{k}=\left(\tilde{a}_{i j}^{k}, \tilde{b}_{i j}^{k}, \tilde{c}_{i j}^{k}\right)$ represents fuzzy judment of expert $k$.

3. The next step is the normalization. Normalized fuzzy decision matrix $\tilde{R}$ is calculated as

$$
\begin{aligned}
& \tilde{R}=\left[\tilde{r}_{i j}\right]_{m * n}, i=1,2, \ldots, m ; j=1,2, \ldots, n \\
& \tilde{r}_{i j}=\left(\frac{a_{i j}}{C_{j}^{+}}, \frac{b_{i j}}{C_{j}^{+}}, \frac{c_{i j}}{C_{j}^{+}}\right), C_{j}^{+}=\max _{i} C_{i j}
\end{aligned}
$$

To avoid the complicated normalization formula used in classical TOPSIS, the linear scale transformation is used to transform the various criteria scales into a comparable scale (Chen, 2000). Linear 
scale transformation for normalization is also employed by Kuo et al. (2007) and Celik et al. (2009).

4. Then, weighted normalized fuzzy decision matrix is computed, where $w_{j}$ is weight for criteria $j$ :

$$
\begin{gathered}
\tilde{v}_{i j}=\tilde{r}_{i j} \otimes \widetilde{w}_{j} \\
\tilde{v}=\left\lfloor\tilde{v}_{i j}\right\rfloor_{m * n}, i=1,2, \ldots, m ; j=1,2, \ldots, n
\end{gathered}
$$

5. Since the TFNs are included in $[0,1]$ range, positive and negative ideal reference points (FPIRP, FNIRP) are as follows:

$$
A^{+}=\left\{\tilde{v}_{1}^{+}, \tilde{v}_{2}^{+}, \ldots, \tilde{v}_{n}^{+}\right\}, A^{-}=\left\{\tilde{v}_{1}^{-}, \tilde{v}_{2}^{-}, \ldots, \tilde{v}_{n}^{-}\right\}
$$

where $\tilde{v}_{j}^{+}=(1,1,1), \tilde{v}_{j}^{-}=(0,0,0)$.

6. The next step is calculating the distance of alternatives from FPIRP and FNIRP:

$$
\begin{aligned}
& d(\tilde{A}, \tilde{B})=\sqrt{\frac{1}{3}\left[\left(a_{1}-b_{1}\right)^{2}+\left(a_{2}-b_{2}\right)^{2}+\left(a_{3}-b_{3}\right)^{2}\right]} \\
& d_{i}^{+}=\sum_{j=1}^{n} d\left(\tilde{v}_{i j}, \tilde{v}_{j}^{+}\right), i=1,2, \ldots, m ; j=1,2, \ldots, n \\
& d_{i}^{-}=\sum_{j=1}^{n} d\left(\tilde{v}_{i j}, \tilde{v}_{j}^{-}\right), i=1,2, \ldots, m ; j=1,2, \ldots, n
\end{aligned}
$$

7. The performance indices are computed in order to rank the alternatives. Performance indices are sorted in decreasing order

$$
C C_{i}=\frac{d_{i}^{-}}{d_{i}^{-}+d_{i}^{+}}, i=1,2, \ldots, m
$$

\section{Case study: Evaluation of e-learning web sites}

E-Learning became an instructional delivery method for the growing number of working adults who sought to earn degrees from universities that provide external programs (Poon et al., 2004). Finance, time or access constraints are minimized with e-learning and an equalopportunity education environment is generated, since e-learning offers cost-effectiveness, timely content and access flexibility to e-learners (Mahdavi et al., 2008). Turkey, a country of $783,562 \mathrm{~km}^{2}$ facing the challenge of providing the same quality education nationwide, benefits from this equal-opportunity environment. ELearning is classically considered to be a new way to empower the workforce with the necessary skills and knowledge (Tzouveli et al., 2008); However, considering the special case of Turkey, where the universities are concentrated on major cities, e-learning stands out as the new era's education provider for not only the workforce, but also for the disadvantaged youth. The current demographics of Turkey where $30.64 \%$ of the population $(20,778,277$ citizens) is made up of 10 to 24-year-olds (Statistics Institute of the Government of Turkey, 2000) engender a very high number of candidates for university education. The annual quota is 500,000 whereas the number of university applicants exceeds 1,600,000 (Student Placement Center, 2008). The severe negative impacts of the capacity constratint, as reflected by the quotas, can be overcome through e-learning, which proposes a great potential to face this educational challenge. Today, nearly all Turkish universities have their own web sites and hence, they seize an incredible opportunity to catch up to developed countries (Kızılsu, 2006). E-Learning activities are broadening within the universities, as well. Many e-programs are executed at the graduate level, and young professionals with time limit and individuals with no access to major cities can profit from the educational added-value of online access.

However, as the number of available online programs increases, the decision process becomes complex. Therefore, the need arises to evaluate the quality of e-learning providers as a pre-requisite of achieving high quality of e-learning in Turkey. In this study web sites of e-learning providers are considered given that the interface greatly influences the e-learner satisfaction with the e-learning system.

The methodology described in Figure 1 is applied to a case study. The goal of this case study is to evaluate and rank the quality performances of e-learning web sites, with the proposed methodology. The web sites are selected from among successful actors operating globally and locally in Turkey. To identify the functional requirements and evaluate the alternatives, three DMs of equal importance, DM1, DM2 and DM3, have been selected amongst e-learning industry experts. These experts are gathered from knowledgeable elearning instructors involved in educational design and implementation of online interfaces. They possess an extended experience in e-learning systems given that they have been the pioneers of the industry.

The e-learning web site evaluation process is performed by applying the following steps:

Step 1. Determination of e-learning web site evaluation criteria

Right and understandable content (C1), Complete content (C2), Personalization (C3), Security (C4), Navigation (C5), Interactivity (C6) and User interface (C7) are the e-learning web site evaluation criteria as discussed in Section 2. 
Step 2. Determination of criteria weights for $e$ learning web site evaluation

Table 2. The consensus linguistic comparison matrix for e-learning web site evaluation criteria.

\begin{tabular}{cccccccc}
\hline & C1 & C2 & C3 & C4 & C5 & C6 & C7 \\
\hline C1 & 1 & P & & & & & \\
C2 & & 1 & & & & & \\
C3 & F & P & 1 & & & & VG \\
C4 & G & F & E & 1 & & & E \\
C5 & G & P & E & F & 1 & E & G \\
C6 & G & F & E & F & & 1 & G \\
C7 & E & G & & & & & 1
\end{tabular}

DMs apply pairwise comparison to evaluate criteria as given in Table 2 and fuzzy AHP given in Section 3.2 is employed with the index of optimism value $\mu=0.5$ in order to determine e-learning web site criteria weights. The obtained results are shown in Table 3.

Table 3. E-Learning web site evaluation criteria weights.

\begin{tabular}{ccccccc}
\hline C1 & C2 & C3 & C4 & C5 & C6 & C7 \\
\hline 0.15 & 0.33 & 0.08 & 0.14 & 0.07 & 0.08 & 0.15
\end{tabular}

\section{Step 3. Determination of alternatives}

To assess the quality of e-learning web sites, 12 web sites given in Table 4 were designated, taking into account experts' opinions in the sector and research conducted through the search engines in January 2008. The first six of these web sites operate worldwide and the remaining six are active only in Turkey. Since the sites all offer mostly common services, the comparison is coherent.

Step 4. DMs' evaluation of web site alternatives and functional requirements

Linguistic terms employed in evaluating e-learning web sites needs to be translated into fuzzy numbers in order to operate on the judgments. In this study, 5-level fuzzy scale is used to assess the alternatives and another 5-level fuzzy scale is used to assess the functional requirements, as a bare minimum for functional requirements. Table 5describes the linguistic terms, their abbreviations and fuzzy membership functions.

As given in Table 5, in the evaluation process, 5level scale was employed to translate linguistic terms into fuzzy numbers. The judgments of DM1 on alternatives isillustrated in Tables 6. The functional requirements of e-learning web sites are defined by three experts and illustrated in Table 7.

Table 4. E-Learning web site alternatives.

\begin{tabular}{cc}
\hline Label & Web address \\
\hline W1 & www.online-degree-enlightenment.com \\
W2 & www.youachieve.com \\
W3 & www.online-education-resources.com \\
W4 & www.universalclass.com \\
W5 & www.sp.edu.sg \\
W6 & www.geolearning.com \\
W7 & www.kidsplus.com.tr \\
W8 & www.ideaelearning.com \\
W9 & www.sanal-kampus.com \\
W10 & www.netron.com.tr \\
W11 & www.enocta.com \\
W12 & www.buelc.boun.edu.tr
\end{tabular}

Step 5. Fuzzification and aggregation of DMs' opinions

DMs' judgments on functional requirements and alternatives given in Step 4 are first translated into fuzzy numbers and then aggregated using the methodology described in Section 3.3. Table 8 displays aggregated evaluations on functional requirements and alternatives.

Table 5. Membership functions for system and design ranges.

\begin{tabular}{|c|c|c|c|c|c|}
\hline Term & Abbr. & Membership & Term & Abbr. & Membership \\
\hline Poor & $\mathrm{P}$ & $0,0,0.3$ & At least poor & LP & $0,1,1$ \\
\hline Fair & $\mathrm{F}$ & $0.2,0.35,0.5$ & At least fair & LF & $0.1,11$ \\
\hline Good & $\mathrm{G}$ & $0.4,0.55,0.7$ & At least good & LG & $0.4,1,1$ \\
\hline Very good & VG & $0.6,0.75,0.9$ & At least very good & LVG & $0.6,1,1$ \\
\hline Excellent & $\mathrm{E}$ & $0.8,1,1$ & At least excellent & LE & $0.8,1,1$ \\
\hline
\end{tabular}


Table 6. Evaluation of alternatives by DM1.

\begin{tabular}{cccccccccccccc}
\hline & W1 & W2 & W3 & W4 & W5 & W6 & W7 & W8 & W9 & W10 & W11 & W12 \\
\hline C1 & VG & VG & VG & F & VG & VG & VG & VG & VG & G & VG & G \\
C2 & E & VG & E & F & VG & F & G & VG & E & G & E & F \\
C3 & F & G & G & VG & G & F & F & G & VG & G & E & VG \\
C4 & P & VG & E & G & VG & G & VG & F & E & VG & E & VG \\
C5 & F & VG & VG & G & F & F & VG & VG & VG & F & VG & G \\
C6 & F & E & VG & G & G & G & G & G & F & F & E & G \\
C7 & F & VG & G & G & VG & VG & VG & G & VG & F & E & G
\end{tabular}

Step 6. Computation of common area and information contents

Once fuzzified evaluations of DMs' judgments are aggregated, fuzzy AD methodology described in section 3.1 is applied to compute the common areas. The greater the common area, better is the response of the alternative to the functional requirements.

Table 7. E-Learning web site functional requirements.

\begin{tabular}{lccccccc}
\hline & C1 & C2 & C3 & C4 & C5 & C6 & C7 \\
\hline DM1 & LG & LG & LP & LG & LP & LP & LF \\
DM2 & LG & LVG & LP & LF & LP & LF & LF \\
DM3 & LG & LVG & LF & LG & LP & LF & LG
\end{tabular}

Computed common areas result in information contents. Table 9 displays information contents for each alternative in response to each criteria and total information content for each alternative. Alternatives that cannot meet functional requirements are eliminated as there are no information content.

Step 7. Calculation of the weighted information contents

Weighted information contents, given in Table 10, are calculated as described in section 3.1.

Step 8. Ranking the e-learning website alternatives
The final ranking is also given in Table 10. Final results demonstrate that two web sites (W6 and W12) are eliminated, meaning that they do not meet the necessary functional requirements. The evaluation results point out that web site $\mathrm{W} 11$ web site has the best performance overall, followed by web site W2.

Step 9. Comparison with Fuzzy TOPSIS

As described in Section 3.4, fuzzy TOPSIS is applied to the aggregated decision matrix in order to compare and justify the outcome of fuzzy AD.

E-Learning web sites were ranked in increasing order of performance index. As seen in Table 11, the outcome of the fuzzy AD methodology is justified with fuzzy TOPSIS. W11 is ranked as the best alternative with both methodologies. Alternatives W6 and W12 are eliminated with fuzzy AD methodology given that these two alternatives cannot meet FR for C2, complete content. However, as fuzzy TOPSIS evaluate the alternatives with respect to FPIRP and FNIRP instead of a set of requirements determined by DMs, alternatives W6 and W12 are considered as well. This comparison of the outcome proves fuzzy AD to be a more suitable methodology to evaluate a large number of alternatives, since a bare minimum for the alternatives can be defined and unsuitable alternatives can easily be eliminated.

Table 8. Aggregated evaluations of DMs.

\begin{tabular}{|c|c|c|c|c|c|c|c|c|c|c|c|c|c|c|c|c|c|c|c|c|c|}
\hline & & C1 & & & $\mathrm{C} 2$ & & & C3 & & & $\mathrm{C} 4$ & & & C5 & & & C6 & & & C7 & \\
\hline FR & & 1.00 & .00 & .53 & 1.00 & 1.00 & 0.03 & & & & 1.00 & & 0.00 & 1.00 & & & 1.00 & & & 1.00 & \\
\hline W1 & & 068 & & & & & & & & & & & & & & & 0.49 & & & & 0.36 \\
\hline W2 & 0.74 & 0.92 & & & 07 & & & & & & & & & & & & & & & & 0.97 \\
\hline W3 & 0.60 & 75 & 0.90 & & 01 & & & & & & & & & 90? & & & 0.92 & & & 0.69 & \\
\hline W4 & & & & & & & & & & & & & & & & & & & & & 0.10 \\
\hline W5 & & م $0 ?$ & & & & & & & & & $0<0$ & & & & & & 0.61 & & & 0.69 & 0.84 \\
\hline W6 & & & & & & & & & & & & & & & & & & & & & 0.84 \\
\hline W7 & & & & & & & & & & & & & & & & & & & & & \\
\hline W8 & & & & & & & & & & & & & & & & & & & & & 0.70 \\
\hline W9 & & 0.68 & & & & & & & & & & & & & & & & & & 0.69 & 0.84 \\
\hline & & 0.49 & 0.64 & & & & & & & & 0.69 & & & 0.35 & & 0.27 & 0.42 & 0.57 & 0.26 & 0.41 & 0.56 \\
\hline W1 & 0.73 & 0.92 & 0.97 & & & & & & & & & & & 0.92 & & 0.73 & 0.92 & 0.97 & 0.66 & 0.83 & 0.93 \\
\hline W12 & 0.33 & 0.48 & 0.63 & 0.20 & 0.35 & 0.50 & 0.60 & 0.75 & 0.90 & 0.53 & 0.68 & 0.83 & 0.53 & 0.68 & 0.83 & 0.46 & 0.61 & 0.76 & 0.40 & 0.55 & 0.70 \\
\hline
\end{tabular}


Table 9. Information contents

\begin{tabular}{ccccccccc}
\hline & $\mathrm{I}_{\mathrm{C} 1}$ & $\mathrm{I}_{\mathrm{C} 2}$ & $\mathrm{I}_{\mathrm{C} 3}$ & $\mathrm{I}_{\mathrm{C} 4}$ & $\mathrm{I}_{\mathrm{C} 5}$ & $\mathrm{I}_{\mathrm{C} 6}$ & $\mathrm{I}_{\mathrm{C} 7}$ & $\mathrm{I}_{\mathrm{TOT}}$ \\
\hline W1 & 0.51 & 0.26 & 1.74 & 3.83 & 0.62 & 0.53 & 3.51 & 11.01 \\
W2 & 0.03 & 0.07 & 0.36 & 0.34 & 0.04 & 0.05 & 0.02 & 0.92 \\
W3 & 0.30 & 0.08 & 0.24 & 0.02 & 0.01 & 0.01 & 0.25 & 0.91 \\
W4 & 2.02 & 7.49 & 0.01 & 0.34 & 0.16 & 0.39 & 0.39 & 10.81 \\
W5 & 0.03 & 0.07 & 0.36 & 0.35 & 0.61 & 0.28 & 0.25 & 1.95 \\
W6 & 0.14 & $\infty$ & 0.89 & 0.81 & 0.82 & 0.74 & 0.24 & $\infty$ \\
W7 & 0.03 & 1.02 & 0.66 & 0.34 & 0.01 & 0.74 & 0.24 & 3.06 \\
W8 & 0.03 & 1.04 & 0.17 & 2.63 & 0.16 & 0.18 & 0.57 & 4.78 \\
W9 & 0.51 & 0.25 & 0.10 & 0.03 & 0.16 & 0.73 & 0.25 & 2.03 \\
W10 & 2.01 & 2.73 & 0.49 & 0.34 & 0.82 & 0.74 & 1.15 & 8.28 \\
W11 & 0.04 & 0.08 & 0.01 & 0.03 & 0.01 & 0.01 & 0.07 & 0.25 \\
W12 & 2.03 & $\infty$ & 0.10 & 0.34 & 0.16 & 0.28 & 0.57 & $\infty$
\end{tabular}

\section{Concluding remarks}

Current developments of information systems facilitate greatly the diffusion of knowledge. Knowledge and education form the source of more than $50 \%$ of the personal national incomes of especially developed western countries and a well educated manpower working at the jobs related with information (Kizılsu, 2006). On the other hand, the advances in information systems and internet change the nature of education (Poon et al., 2004). Therefore, education activities transfer to electronic platforms for higher speed and less effort. Consequently, the web sites hosting the e-learning system become an important interface for the end-user and web site quality directly affects e-learning provider's performance. Therefore, a performance analysis based on MDCM techniques is applied to measure the quality of e-learning web sites.
More precisely, in this paper, a group decision based fuzzy AD methodology was applied to the problem of ranking e-learning web sites. The proposed methodology is expected to provide additional contribution and decision support to the managers working in the learning and e-business industries, due to its advantages over already established techniques, such as fuzzy TOPSIS. Specifically, the proposed methodology incorporates functional requirements into the ranking and selection process, and can identify the alternatives that do not comply with the requirements.

For future research, the set of alternatives can be further extended and a two-stage MCDM analysis consisting of pre-assessment and detailed evaluation can be applied in order to thoroughly review e-learning web site alternatives. Given that service web sites are increasing in number, pre-assessment stage will eliminate rapidly the unsuitable candidates with general criteria and minimum assessment of alternatives, preferably with a single expert. A more meticulous evaluation with fewer alternatives will be realized with a hierarchic structure of criteria and a more detailed assessment of a group of expert. Also, criteria set may be altered to evaluate web sites other than e-learning, such as e-commerce, hospital, and bank web sites, based on the proposed methodology, since the general scheme of criteria can be applied to all web sites with only a few changes.

\section{Acknowledgements}

The authors acknowledge the contribution of the expert committee members without which this study could not be accomplished. Gülçin Büyüközkan acknowledges

Table 10. Weighted information contents and rankings

\begin{tabular}{|c|c|c|c|c|c|c|c|c|c|c|c|c|}
\hline & W1 & W2 & W3 & W4 & W5 & W6 & W7 & W8 & W9 & W10 & W11 & W12 \\
\hline WI & 1.45 & 0.11 & 0.13 & 2.93 & 0.21 & $\infty$ & 0.54 & 0.84 & 0.28 & 1.58 & 0.05 & $\infty$ \\
\hline Ranking & 8 & 2 & 3 & 10 & 4 & Eliminated & 6 & 7 & 5 & 9 & 1 & Eliminated \\
\hline
\end{tabular}

Table 11. Performance indices and rankings

\begin{tabular}{ccccccccccccccccccc}
\hline & W1 & W2 & W3 & W4 & W5 & W6 & W7 & W8 & W9 & W10 & W11 & W12 \\
\hline PI & 0.08 & 0.12 & 0.12 & 0.08 & 0.11 & 0.08 & 0.10 & 0.10 & 0.11 & 0.08 & 0.13 & 0.08 \\
Ranking & 10 & 2 & 3 & 8 & 4 & 12 & 6 & 7 & 5 & 11 & 1 & 9
\end{tabular}


also the financial support of the Galatasaray University Research Fund.

\section{References}

1. A.M. Aladwani and P.C. Palvia, Developing and validating an instrument for measuring user-perceived web quality, Information \& Management 39 (2002) 467476.

2. E. Colette, Electronic education system model, Computers \& Education 36 (2001) 171-182.

3. H. Chao, Assessing the quality of academic libraries on the Web: The development and testing of criteria, Library \& Information Science Research 24 (2002) 169-194.

4. J. Cox and B.G. Dale, Key quality factors in web site design and use: an examination, International Journal of Quality \& Reliability Management 19 (2002) 862-888.

5. M. Jeong, H. Oh, and M. Gregoire, Conceptualizing web site quality and its consequences in the lodging industry, International Journal of Hospitality Management 22 (2003) 161-175.

6. S-E. Kim, T. Shaw, and H. Schneider, Web site design benchmarking within industry groups, Internet Research: Electronic Networking Applications and Policy 13 (2003) $17-26$.

7. S-E. Kim and L. Stoel, Dimensional hierarchy of retail website quality, Information \& Management 41 (2004) 619-633.

8. E.G. Toms and A.R. Taves, Measuring user perceptions of web site reputation, Information Processing and Management 40 (2004) 291-317.

9. R. van der Merwe and J. Bekker, A framework and methodology for evaluating e-commerce web sites, Internet Research: Electronic Networking Applications and Policy 13 (2003) 330-341.

10. S.J. Barnes and R. Vidgen, Measuring Web site quality improvements: a case study of the forum on strategic management knowledge exchange, Industrial Management \& Data Systems 103 (2003) 297-309.

11. F.J.M. Gonzalez and T.M.B. Palacios, Quantitative evaluation of commercial web sites: an empirical study of Spanish firms, International Journal of Information Management, 24 (2004) 313-328.

12. G-J. Hwang, T.C.K. Huang, and J.C.R. Tseng, A groupdecision approach for evaluating educational web sites, Computers \& Education, 42 (2004) 65-86.

13. R.U. Bilsel, G. Büyüközkan, and D. Ruan, A fuzzy preference-ranking model for a quality evaluation of hospital web sites, International Journal of Intelligent Systems, 21 (2006) 1181-1197.

14. N.P. Suh, Axiomatic design; advanced applications. (Oxford University Press, New York, 2001).

15. S.J. Kim, N.P. Suh, and S. Kim, Design of software systems based on AD, Annals of CIRP 40(1) (1991) 165170.
16. N.P. Suh, Designing-in of Quality Through Axiomatic Design, IEEE Transactions On Reliability 44(2) (1995a) 256-264.

17. N.P. Suh, Design and operation of large systems, Annals of CIRP 44 (3) (1995b) 203-213.

18. N.P. Suh, Design of systems, Annals of CIRP 46(1) (1997) 75-80.

19. N.P. Suh, D.S. Cochran, and C.L. Paulo, Manufacturing system design, CIRP Annals 47(2) (1998) 627-39.

20. D.S. Cochran, J.A. Arinez, W.D. Duda, and J. Linck, A decomposition approach for manufacturing system design, Journal of Manufacturing Systems 20(6), 371389.

21. M.G. Helander and L. Lin, Axiomatic design in ergonomics and an extension of the information axiom, Journal of Engineering Design 13(4) (2002) 321-339

22. M.D. Guenov and S.G. Barker, Application of axiomatic design and design structure matrix to the decomposition of engineering systems, Systems Engineering 8(1) (2005) 29-40.

23. J. Thielman and P. Ge, Applying axiomatic design theory to the evaluation and optimization of large-scale engineering systems, Journal of Engineering Design 17(1) (2006) 1-16.

24. M. Durmusoglu and O. Kulak, A methodology for the design of office cells using axiomatic design principles, Omega 36 (2008) $633-652$.

25. S.B. Martin and A.K. Kar, Axiomatic Design for the development of enterprise level e-commerce strategies, in Proceedings of ICAD 2002, Second International Conference on Axiomatic Design (MIT, Cambridge, USA, 2002).

26. M.M. Yenisey, Axiomatic Design Approach for ECommercial Web Sites, Lecture Notes in Computer Science 4550 (2007) 308-315.

27. C. Kahraman and O. Kulak, Fuzzy multi-attribute decision making using an information axiom based approach, in Fuzzy multi-criteria decision-making theory and applications with recent developments (Springer, New York, 2005).

28. L.A. Zadeh, The concept of a linguistic variable and its applications to approximate reasoning, Information Sciences 8 (1975) 199-249 (I); 301-357 (II).

29. O. Kulak and C. Kahraman, Multi-attribute comparison of advanced manufacturing systems using fuzzy vs. crisp axiomatic design approach, International Journal of Production Economics 95 (2005a) 415-424.

30. O. Kulak and C. Kahraman, Fuzzy multi-attribute selection among transportation companies using axiomatic design and analytic hierarchy process, Information Sciences 170 (2005b) 191-210.

31. O. Kulak, A decision support system for fuzzy multiattribute selection of material handling equipments, Expert Systems with Applications 29(2) (2005) 310-319.

32. G. Yücel and E. Aktas, An Evaluation Methodology for Ergonomic Design of Electronic Consumer Products Based on Fuzzy Axiomatic Design, Journal of Multiple- 
Valued Logic and Soft Computing 15(2-3) (2008) 181208.

33. C. Kahraman and S. Cebi, A new multi-attribute decision making method: Hierarchical fuzzy axiomatic design, Expert Systems with Applications 36(3) (2009) 48484861.

34. M. Celik, C. Kahraman, S. Cebi, and I.D. Er, Fuzzy axiomatic design-based performance evaluation model for docking facilities in shipbuilding industry: The case of Turkish shipyards, Expert Systems with Applications 36(1) (2009a) 599-615.

35. M. Celik, C. Kahraman, S. Cebi, and I.D. Er, Application of axiomatic design and TOPSIS methodologies under fuzzy environment for proposing competitive strategies on Turkish container ports in maritime transportation network, Expert Systems with Applications 36(3) (2009b) 4541-4557.

36. M. Celik, S. Cebi, C. Kahraman, and I.D. Er, An integrated fuzzy QFD model proposal on routing of shipping investment decisions in crude oil tanker market source, Expert Systems with Applications 36(3) (2009c) 6227-6235.

37. M. Celik, A hybrid design methodology for structuring an Integrated Environmental Management System (IEMS) for shipping business, Journal of Environmental Management 90(3) (2009) 1469-1475.

38. E. Cevikcan, S. Cebi, and I. Kaya, Fuzzy VIKOR and Fuzzy Axiomatic Design Versus to Fuzzy Topsis: An Application of Candidate Assessment, Journal of Multiple-Valued Logic and Soft Computing 15(2-3) (2009) 181-208.

39. P. Tzouveli, P. Mylonas, and S. Kollias, An intelligent elearning system based on learner profiling and learning resources adaptation, Computers \& Education 51 (2008) 224-238

40. W.-C. Poon, K.L.-T. Low, and D.G.-F. Yong, A study of Web-based learning (WBL) environment in Malaysia, The International Journal of Educational Management 18(6) (2004) 374-385.

41. T. Ahn, S. Ryu, and I. Han, The impact of Web quality and playfulness on user acceptance of online retailing, Information \& Management 44 (2007) 263-275.

42. H.W. Webb and L.A. Webb, SiteQual: an integrated measure of Web site quality, The Journal of Enterprise Information Management 17 (2004) 430-440.

43. I. Mahdavi, H. Fazlollahtabar, A. Heidarzade, N. Mahdavi-Amiri, and Y.I. Rooshan, A Heuristic Methodology for Multi-Criteria Evaluation of WebBased E-Learning Systems Based on User Satisfaction, Journal of Applied Sciences 8(24) (2008) 4603-4609.

44. S.W. Kim and M.G. Lee, Validation of an evaluation model for learning management systems, Journal of Computer Assisted Learning 24(4) (2008) 284-294.

45. M. McPherson and J. Nunest, Critical issues for elearning delivery: what may seem obvious is not always put into practice, Journal of Computer Assisted Learning 24(5) (2008) 433-445.
46. A.G. Smith, Applying evaluation criteria to New Zealand government websites, International Journal of Information Management 21 (2001) 137-149.

47. N-G. Dragulanescu, Website quality evaluations: criteria and tools, International Information \& Library Review 34 (2002) 247-254.

48. Y-S. Wang, Assessment of learner satisfaction with asynchronous electronic learning systems, Information \& Management 41 (2003) 75-86.

49. S.J. Barnes and R. Vidgen, Data Triangulation and Web Quality Metrics: A Case Study in E-Government, Information \& Management, 43(6) (2006) 767-777.

50. G. Büyüközkan, D. Ruan, and O. Feyzioğlu, Evaluating e-learning web site quality in a fuzzy environment, International Journal of Intelligent Systems 22(5) (2007) 567-586.

51. E. Grigoroudis, C. Litos, V.A. Moustakis, Y. Politis, and L. Tsironis, The assessment of user-perceived web quality: Application of a satisfaction benchmarking approach, European Journal of Operational Research 187(3) (2008) 1346-1357.

52. M.J. van den Haak, M.D.T. de Jong, and P.J. Schellens, Evaluating municipal websites: A methodological comparison of three think-aloud variants, Government Information Quarterly 26(1) (2009) 193-202

53. R. Gonzalez, J. Gasco, and J. Llopis, E-government success: some principles from a Spanish case study, Industrial Management \& Data Systems, 107 (2007) 845861.

54. F. Herrera, E. Herrera-Viedma, and F. Chiclana, Multiperson decision-making based on multiplicative preference relations, European Journal of Operational Research, 129 (2001) 372-385.

55. J. Lu, G. Zhang, F. Wu, Team Situation Awareness Using Web-based Fuzzy Group Decision Support Systems, International Journal of Computational Intelligence Systems, 1(1) 200850 - 59.

56. X. Li, D. Ruan, J. Liu, Y. Xu, A Linguistic-Valued Weighted Aggregation Operator to Multiple Attribute Group Decision Making with Quantative and Qualitative Information, International Journal of Computational Intelligence Systems, 1(3) (2008) 274 - 284.

57. L-S. Chen and C-H. Cheng, Selecting IS personnel use fuzzy GDSS based on metric distance method, European Journal of Operational Research 160 (2005) 803-820.

58. Y-M. Wang and C. Parkan, Optimal aggregation of fuzzy preference relations with an application to broadband internet service selection, European Journal of Operational Research 187 (2008) 1476-1486.

59. C-H. Yeh and Y-H. Chang, Modeling subjective evaluation for fuzzy group multicriteria decision making, European Journal of Operational Research 194 (2009) 464-473.

60. N. P. Suh, The principles of design (Oxford University Press, New York, 1990).

61. T. L. Saaty, The analytic hierarchy process (McGrawHill Book Company, New York, 1980). 
62. L.A. Zadeh, Fuzzy Sets, Information \& Control 8 (1965) 338-353.

63. T.L. Saaty, 1989. Decision making, scaling, and number crunching, Decision Sciences 20 (1989) 404-409.

64. A.R. Lee, Application of Modified Fuzzy AHP Method to Analyze Bolting Sequence of Structural Joints (UMI Dissertation Services, A Bell \& Howell Company, 1999).

65. S.M. Chen, Aggregating fuzzy opinions in the group decision making environment. Cybernetics and Systems 29 (1998) 363-376.

66. S.J. Chen and C.L. Hwang, Fuzzy Multiple Attribute Decision Making: Methods and Applications (SpringerVerlag, Berlin, 1992)

67. S. Saghafian and S.R. Hejazi, Multi-criteria Group Decision Making Using A Modified Fuzzy TOPSIS Procedure, in Proceedings of the Computational Intelligence for Modelling, Control and Automation, 2005 and International Conference on Intelligent Agents, Web Technologies and Internet Commerce.

68. S.H. Tsuar, T.Y. Chang, and C.H. Yen, The evaluation of airline service quality by fuzzy MCDM, Tourism Management 23 (2002) 107-115.

69. H. Deng, C.H. Yeh, and R.J. Willis, Inter-company comparison using modified TOPSIS with objective weights, Computers \& Operations Research 27 (2000) 963-973.

70. R.C. Wang and T.F. Liang, Application of fuzzy multiobjective linear programming to aggregate production planning, Computers \& Industrial Engineering 46 (2004) $17-41$.

71. T.C. Chu, Facility location selection using fuzzy TOPSIS under group decisions, International Journal of Uncertainty, Fuzziness and Knowledge-Based Systems 10(6) (2002) 687-701.

72. M.A. Abo-Sina and A.H. Amer, Extensions of TOPSIS for multiobjective large-scale nonlinear programming problems, Applied Mathematics and Computation 162 (1) (2005) 243-256

73. M.N. Qureshi, P. Kumar, and D. Kumar, 3PL Evaluation and Selection Under a Fuzzy Environment: A Case Study, The Icfai Journal of Supply Chain Management 5 (2008) 38-53.

74. H-S. Shih, Incremental analysis for MCDM with an application to group TOPSIS, European Journal of Operational Research 186 (2008) 720-734.

75. C-T. Chen, Extensions of the TOPSIS for group decisionmaking under fuzzy environment, Fuzzy Sets and Systems 114 (2000) 1-9.

76. M-S. Kuo, G-H. Tzeng, and W-C. Huang, Group decision-making based on concepts of ideal and anti-ideal points in a fuzzy environment, Mathematical and Computer Modeling 45 (2007) 324-339.

77. Statistics Institute of the Government of Turkey, Yaş Grubu ve Cinsiyete Göre Nüfus 2000 (Population statistics based on age group and gender), http://tuik.gov.tr/PreIstatistikTablo.do?istab_id=219
78. Student Placement Center, ÖSYM 2008 Yll Faaliyet Raporu (Annual Report 2008), page 58. Retrieved on October 2009, http://www.osym.gov.tr

79. G. Kizılsu, Dimensions of E-Learning Education in Turkey, in FIG Workshop on eGovernance, Knowledge Management and eLearning (Budapest, Hungary, 2006). 